\title{
VOLUMETRIC RECONSTRUCTION OF THE HEART IN HEALTH AND IN DISEASE: A RADIOLOGICAL STUDY
}

\author{
BY
}

\author{
JOHN D. SPILLANE
}

From the Department of Cardiology, Massachusetts General Hospital, Boston, U.S.A.

Received May 12, 1939

Radiological study of the heart has now become a well-recognized and valuable procedure in the investigation of a cardiac patient ; certain changes in heart shape and size can only be demonstrated by this method. The rationale of fluoroscopy of the heart is that by rotating the patient into suitable positions each chamber may be made to form a border, so that a measure of its size and depth is obtained. The value and limitations of the radiological approach can be estimated only on the basis of a knowledge of the relative size and position of these chambers. To the student fresh from the dissecting and post-mortem rooms there is a bewildering difference between the configuration and relative anatomy of the heart chambers before and after removal of the organ from the body. To help to obviate this difficulty it was thought worth while to reconstruct, in permanent form, a series of life-size models of normal and diseased hearts, the study of which would enable the student to appreciate more readily the radiological changes of heart disease. This paper deals with the manner of their reconstruction, with a description of each model. In addition, a few remarks about some more or less controversial points in the gross anatomy of the heart and great vessels are included.

\section{The Method of Reconstruction}

The first step in the procedure was devised by Palmieri (1921) and, although in itself it has not any important clinical application, it provides us with a clay replica of the heart that forms the basis of our final reconstruction; in Fig. 1 is illustrated the principle of the method.

First Stage.-This is entirely a fluoroscopic procedure, the object being to obtain a series of tracings of the cardiovascular silhouette in different degrees of rotation of the patient. The patient is placed on a revolving stool, the vertical axis of which passes approximately through the centre of the heart. The X-ray tube is at the ordinary distance from the patient. The distances of the tube from the heart axis and from the fluoroscopic screen are measured and recorded ; these are kept constant in all examinations. By central (not 


\section{Ist STAGE}

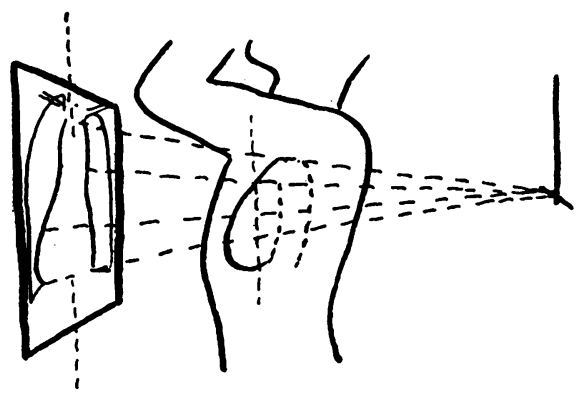

\section{2nd STAGE}

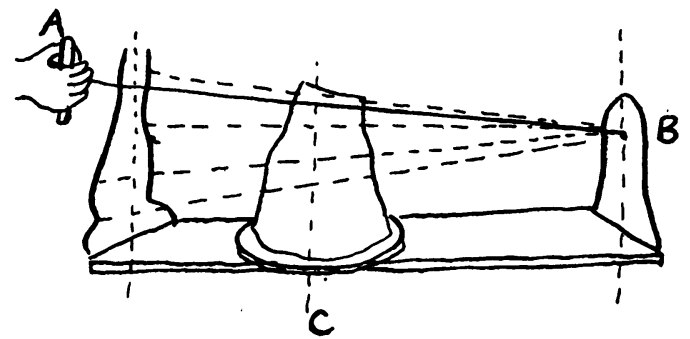

FIG. 1.-Diagram illustrating Palmieri's method of radiological volumetric reconstruction of the heart. First stage : by fluoroscopic examination in different degrees of rotation of the patient tracings are obtained of the cardiovascular silhouette by central projection. Second stage : the tracings are cut out in cardboard and, with the apparatus shown, a length of wire $A B$ is moved along the edge of the cardboard section and pieces from a block of plastic material $\mathrm{C}$ are cut off. With each cardboard section the block is rotated into the corresponding position. When the manœuvre is completed a replica of the heart is obtained. (Modified from Palmieri (1921).)

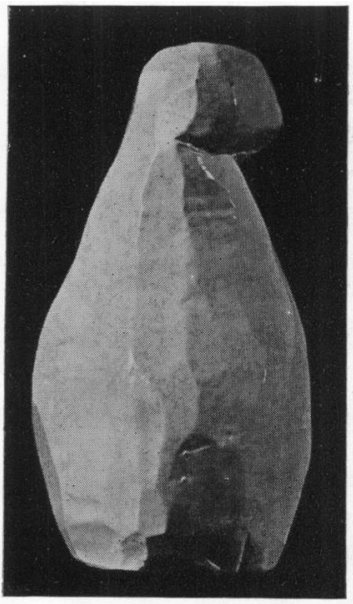

L.O.

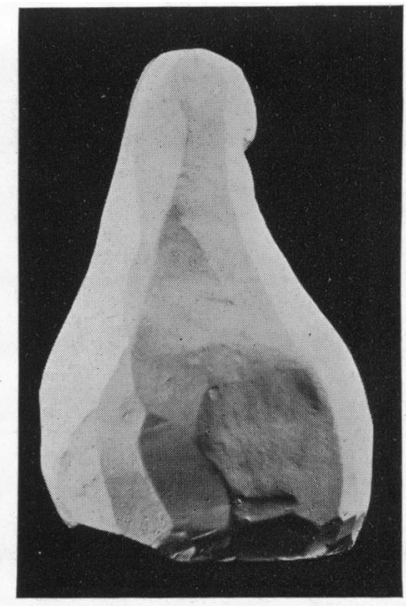

ANT.

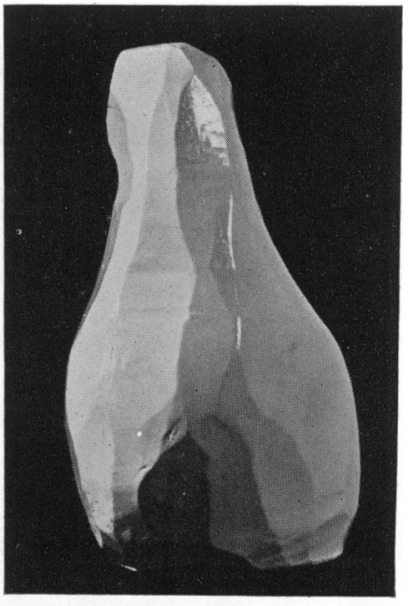

R.O.

Fig. 2.-Clay replica of a normal heart obtained by Palmieri's method. Anterior, left and right oblique views. 
orthodiagraphic) projection a tracing of the heart and great vessels is made on the screen in the anterior position. The tracing is made with lipstick so that a sheet of paper pressed against the screen will record the outline obtained.

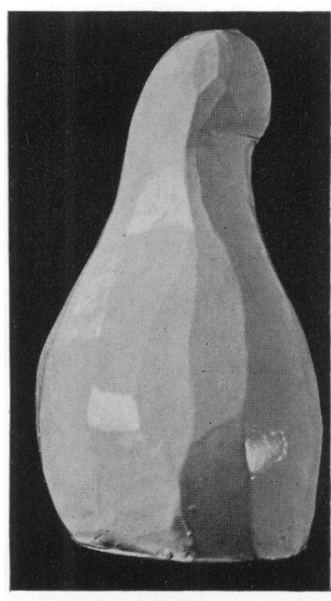

L.O.

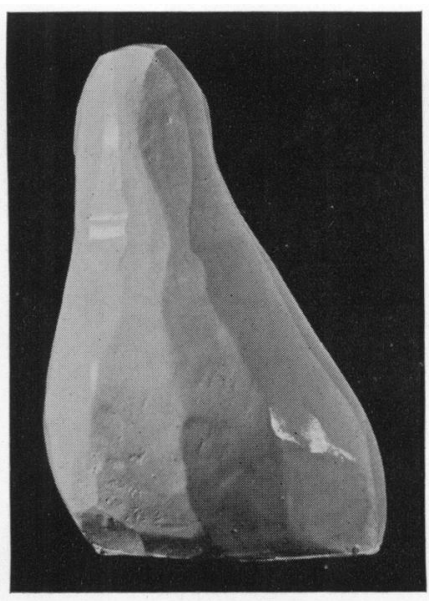

ANT.

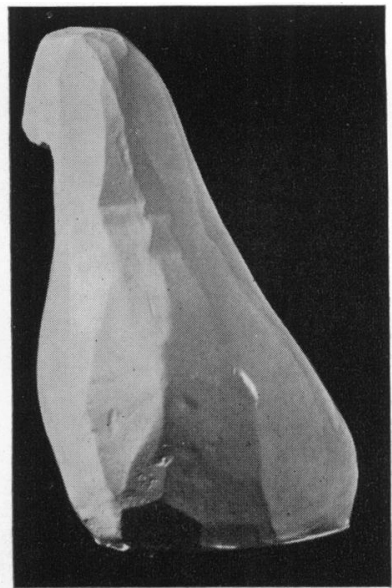

R.O.

FIG. 3.-Clay replica of a normal vertical heart, with low diaphragm. Anterior, left and right oblique views.

The markings on the screen are then erased, the patient rotated through 30 degrees and a second tracing made. Of course, the heart shadow must be centred before each tracing. The use of lipstick renders it possible rapidly

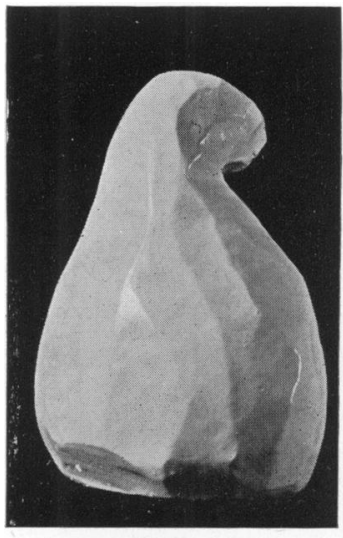

L.O.

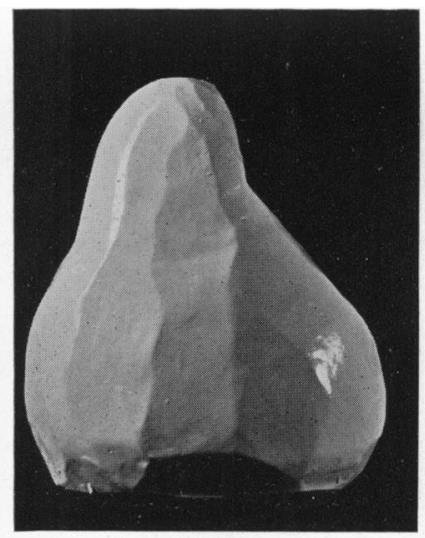

R. O.

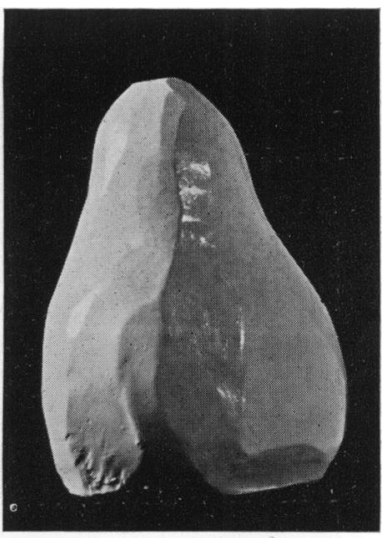

ANT.

FIG. 4.-Clay replica of a normal transverse heart, with high diaphragm. Anterior, left and right oblique views.

to transfer the tracing from screen to paper in the dark, thus avoiding the necessity of interrupting the pupillary accommodation. Twelve tracings are made of the heart outline in different projections by rotating the patient through 360 degrees. The angle at which each drawing is made is recorded. Certain 


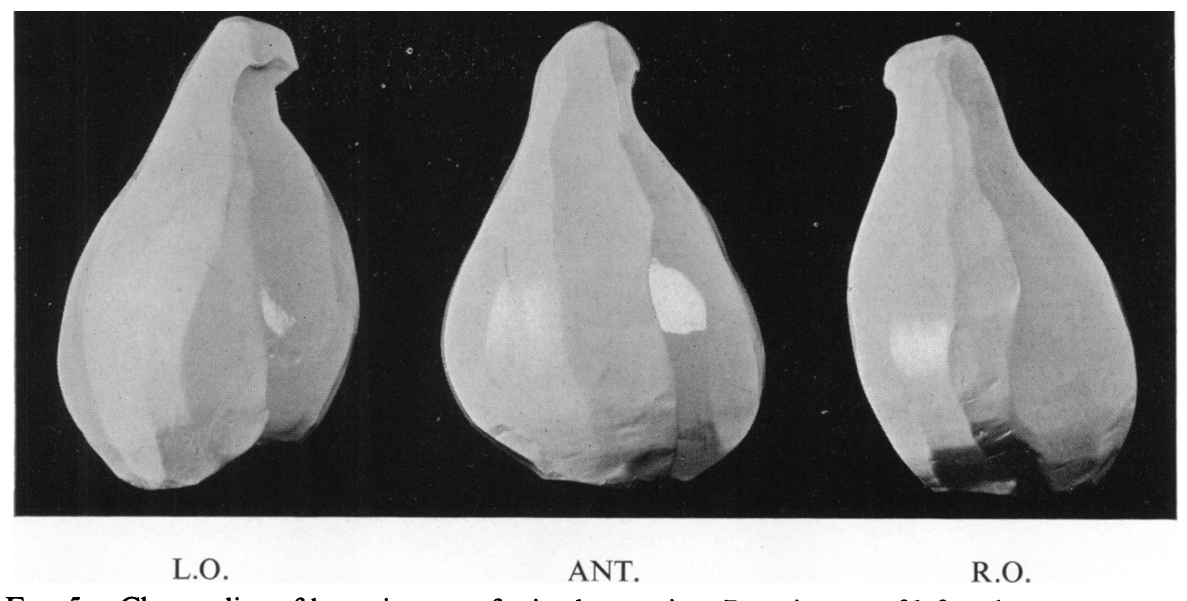

Fig. 5.-Clay replica of heart in case of mitral stenosis. Prominence of left pulmonary artery and conus in anterior view ; bulging of left auricle in right and left oblique views ; enlargement of right side of heart. Anterior, left and right oblique views.

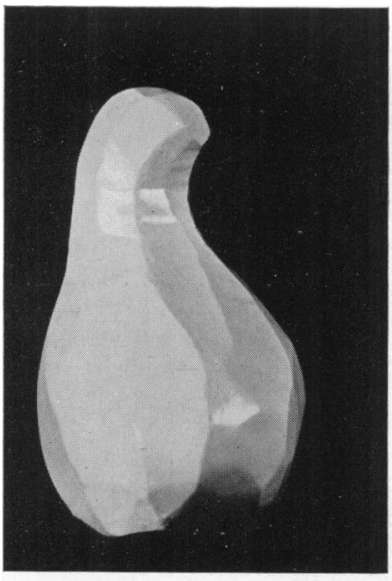

L.O.

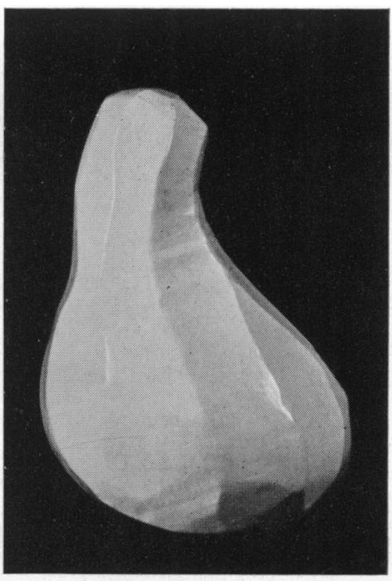

ANT.

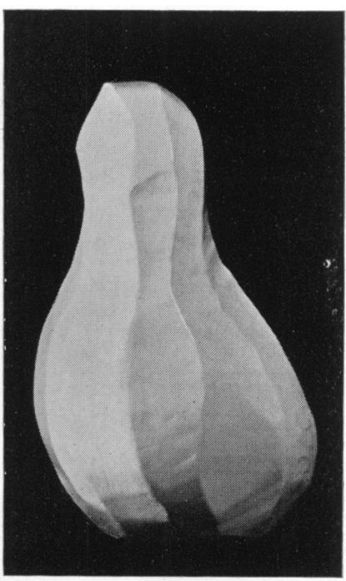

R.O.

FIg. 6.-Clay replica of heart in case of free aortic regurgitation, showing prominent aortic knob and enlargement of left ventricle. Anterior, left and right oblique views.
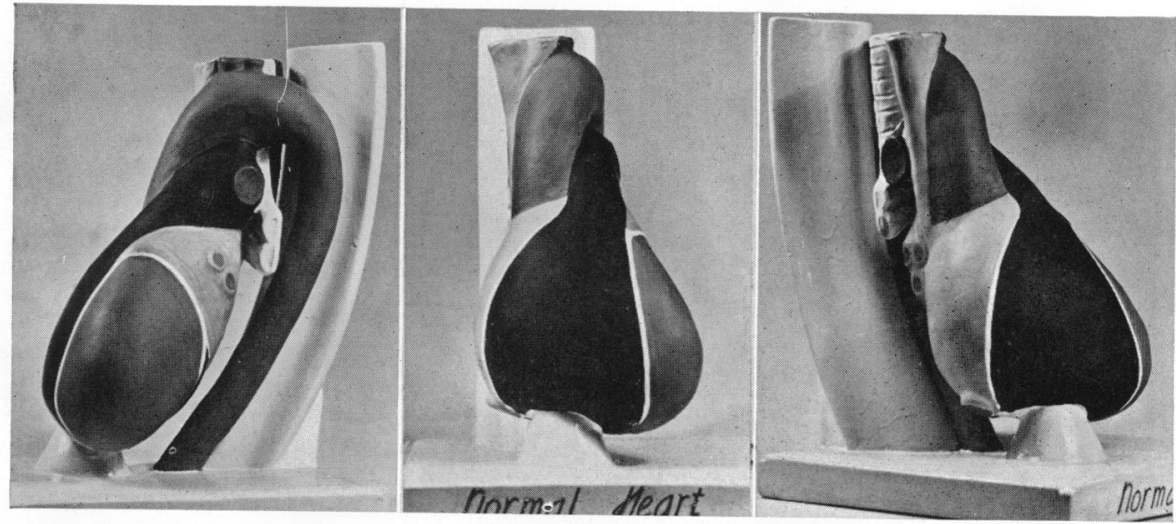

ANT,

R.O.

Fig. 7.-Model 1. Average normal heart. A modification of Taipale's model (1934). The correct juxtaposition of esophagus and arch of the aorta is shown; the convexity of the right heart border has been reduced by narrowing the width of the base of the right ventricle ; the apex of the heart is formed entirely by the left ventricle ; the left auricular salient is reduced. 
difficulties arise which make it impossible to obtain a complete outline in every view. The diaphragmatic surface of the right ventricle is not visualized in the anterior view ; in young people the arch of the aorta and the posterior border of the left auricle are difficult to make out in the left lateral and oblique views ; in the postero-anterior view, the upper segment of the left heart border is partly hidden. In spite of these limitations, prolonged accommodation of the eyes in the dark room and repeated examinations made it possible to obtain such tracings in a number of patients with the commoner forms of heart disease.

Second Stage.-The paper tracings are cut out in stiff cardboard and, with the apparatus shown in Fig. 1, a replica of the heart is cut off from a block of plastic material. The apparatus consists of a plank of wood equal in length to the measured distance between the X-ray tube and the screen. At C, a point corresponding to the vertical axis of the revolving stool (and of the

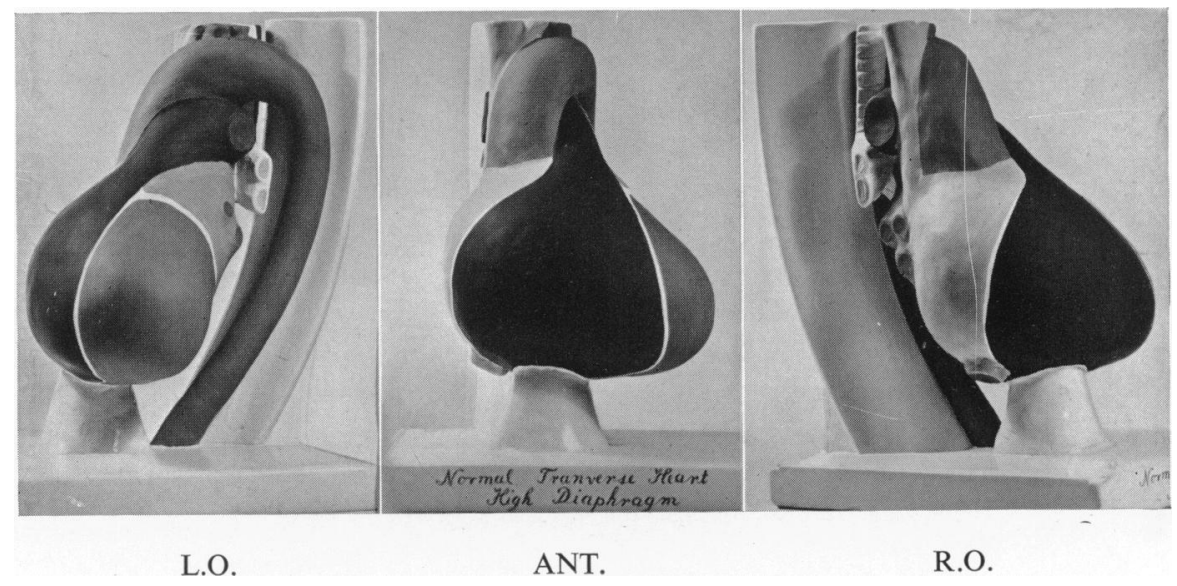

FIG. 8.-Model 2. Transverse type of heart. The axis is approximately at right-angles to the great vessels. The level of the cardio-aortic junction is raised and the vascular pedicle is shortened. The transverse diameters of heart and vascular pedicle are increased. In the left oblique view the arch of the aorta is curved on a large radius. The retrocardiac space is increased.

patient's heart), a hole is bored and over this is placed a disc of wood marked off in degrees. A block of soft artist's modelling clay is centred about this axis on the wooden disc. At one end is a wooden upright to which is fastened a length of piano wire $A B$; the point $B$ corresponds to the position of the centre of the X-ray tube. At the other end are placed two grooved uprights which serve to hold the cardboard sections in position. Thus the screen is replaced by the cardboard sections, the body of the patient by a block of plastic material, and the tangential X-ray beam by the length of piano wire.

The first cardboard section, showing the cardiovascular silhouette in the anterior view, is placed in position and the wire moved along the edge ; and in so doing it cuts off a part of the clay. The latter is then rotated through 30 degrees when the corresponding section is inserted and the manœuvre repeated. When each heart outline has been cut and the clay has been rotated through 360 degrees, the replica of the heart is complete. It is a fairly accurate 
reconstruction of the body of the heart and part of the aortic arch. Such clay models then serve as the foundation for our final reconstruction. Figs. 2, 3, 4, 5 , and 6 illustrate plaster casts of such clay replicas.

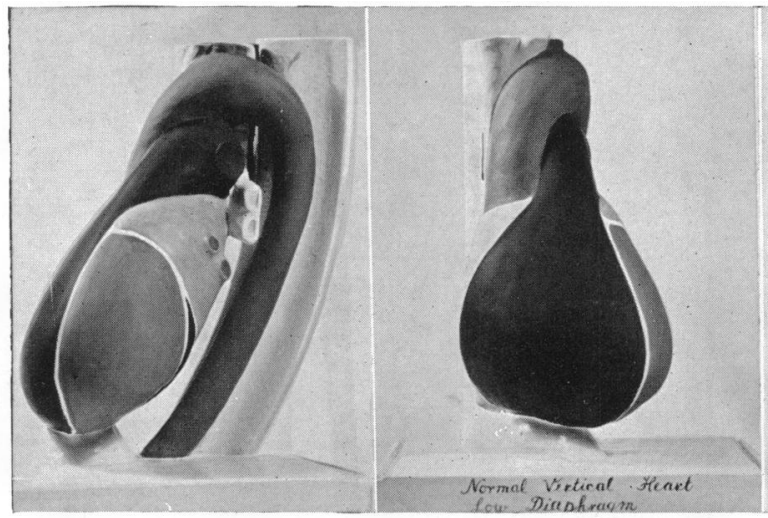

L.O.
ANT.

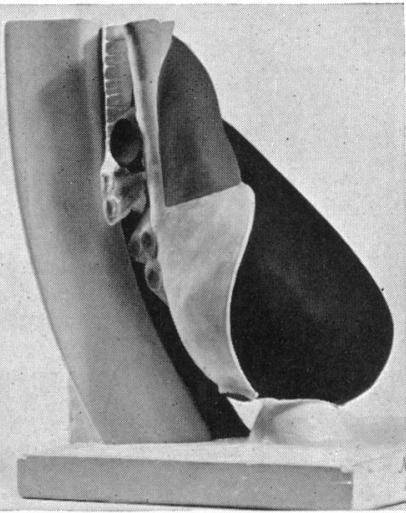

R.O.

FIG. 9.-Model 3. Vertical type of heart. The transverse diameters of the heart and the vascular pedicle are both reduced. The diaphragm is low in position and the convexity of all contours in all views is only slightly prominent. The right ventricle may participate to a small degree in the right heart border. The arch of the aorta appears short in the left anterior oblique view and is curved on a small radius. Both the dorsal and ventral cardiac contours are rather flat. The retrocardiac space is comparatively small.

Third Stage.-Palmieri's reconstruction did not proceed beyond the second stage. However, Taipale (1934) has constructed a porcelain model of a normal

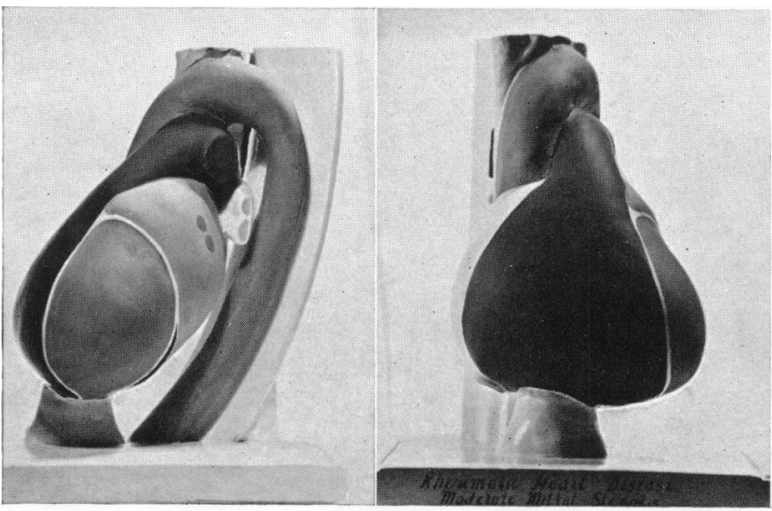

L.O.

ANT.

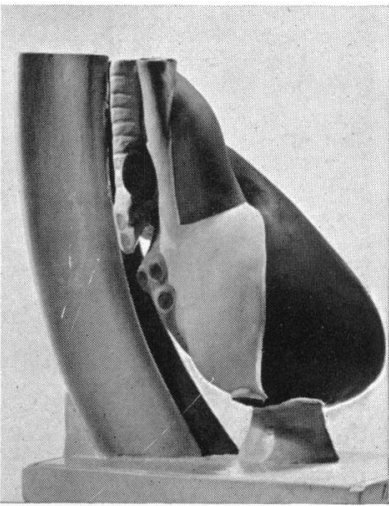

R.O.

FIG. 10.-Model 4. Moderate mitral stenosis. Anterior view shows straightening of left heart border, due to prominence of pulmonary artery and conus and left auricle. Moderate dilatation of the pulmonary artery. Left anterior oblique view shows enlargement of the left auricle. The retrocardiac space is diminished especially in its upper and middle thirds. There is no elevation of the left main bronchus.

heart which was based on many fluoroscopic examinations. Although not free from error, it is undoubtedly one of the most useful models yet made, especially from the radiological point of view. For this reason, and because 
of the high degree of artistic finish of the model, it was decided to fashion our own abnormal models on similar lines, but owing to the prohibitive cost of porcelain manufacture it was arranged to cast our model in plaster.

A wooden armature was constructed, consisting of a base, $71 / 2$ inches square and 1 inch in thickness, with an upright $81 / 2$ inches in height carved to represent the vertebral column. The clay replica was placed in position in front of the column, supported on a wooden pedestal and transfixed in its vertical axis by a screw driven through the base. With this as a foundation, the position of the heart chambers, interventricular, and auriculo-ventricular grooves were indicated and the great vessels, œsophagus, and trachea built up according to their position as outlined at fluoroscopy. Deviations of the osophagus were

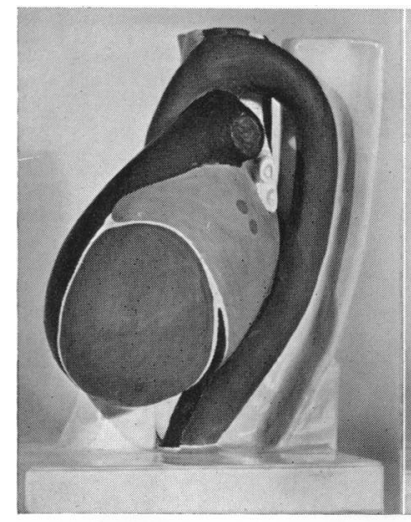

L.O.

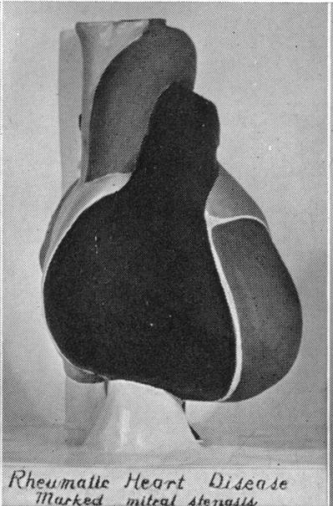

ANT.

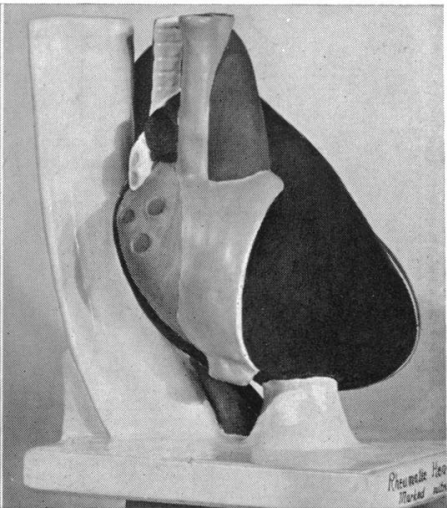

R.O.

Fig. 11.-Model 5. Marked mitral stenosis. Left auricular enlargement causes a convexity on the left heart border below the dilated pulmonary artery and conus. In the anterior view the left auricle can be seen on the right border of the heart, projecting above and behind the right auricle. Enlargement of the left auricle has obliterated the upper twothirds of the retrocardiac space and has elevated the angle of bifurcation of the trachea and left bronchus. The œsophagus is displaced to the right by the enlarged left auricle and takes a wide sweep before it crosses to the left side of the descending aorta just above the diaphragm. In the lateral view the prominent pulmonary artery and conus make the anterior heart border convex. There is moderate dilatation of the right ventricle and right auricle.

detected by a barium swallow, and the position of the trachea recorded as accurately as possible. It was not considered necessary to outline the tracheal bifurcation with lipiodol. The intraventricular notch could not be visualized in each case and the position of the auriculo-ventricular grooves had to be obtained from observations on post-mortem controls. The position of the diaphragm was indicated by raising or lowering the pedestal upon which the heart rested. Except when the width of the descending aorta could be readily measured, an average was struck and maintained in all models in which the aorta was normal.

On completing such a model in clay, it was cast in plaster, shellacked, coloured, and inscribed. Twelve such models have been completed and they are illustrated in Figs. 7-18 of this paper with a description of each, with photographs in the anterior, left oblique, and right oblique views. 


\section{Some Anatomical Comments of Radiological InTERest}

One error in Taipale's model of the normal heart needed correction; it concerned the position of the esophagus in its relationship to the arch of the aorta. Taipale failed to show that the œsophagus normally receives an

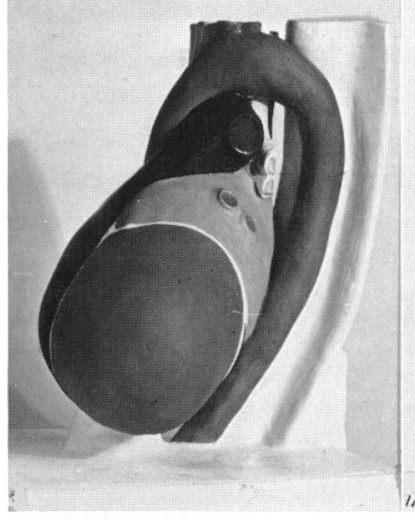

L.O.

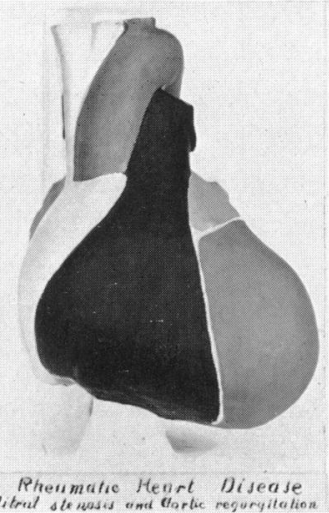

ANT.

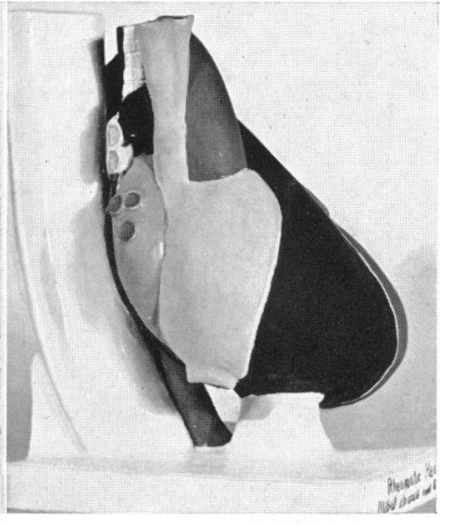

R.O.

FIG. 12.-Model 6. Mitral stenosis and aortic regurgitation. Besides the features of mitral stenosis, as described in Model 5, there is also marked left ventricular enlargement, due to aortic incompetence. In the left oblique view the lower third of the retrocardiac space is largely obliterated by the enlarged left ventricle.

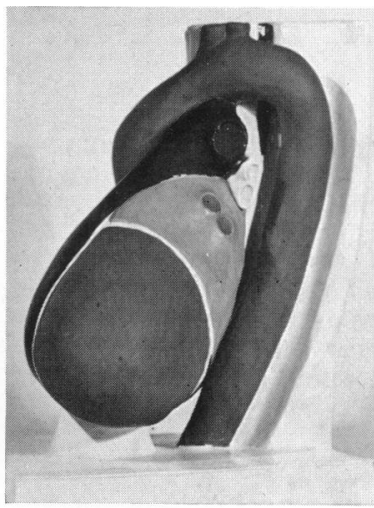

L.O.

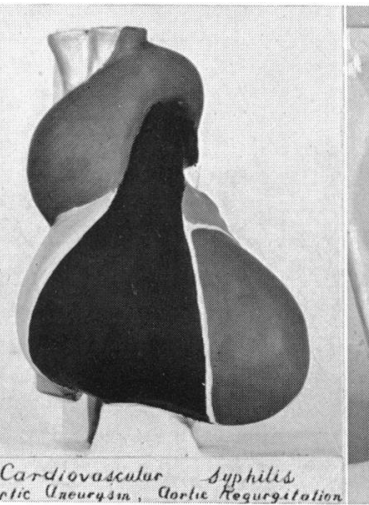

ANT.

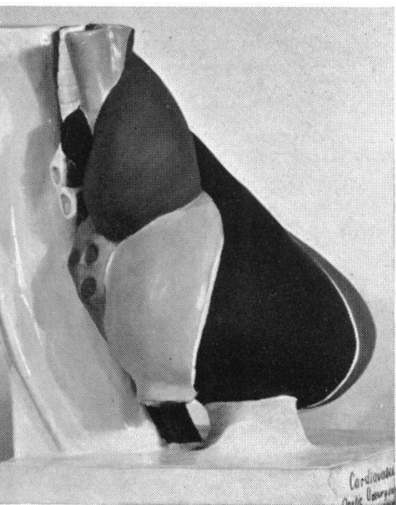

R.O.

FIG. 13.-Model 7. Aneurysm of the ascending limb of the aortic arch, with aortic incompetence. The left ventricle is enlarged. The aneurysm projects to the right beyond the right margin of the superior vena cava, which is displaced posteriorly and to the right. The aortic knob is prominent, presenting a marked convexity on the upper left border of the vascular pedicle. The trachea and œsophagus are displaced posteriorly and the latter is compressed against the vertebral column.

impression, roughly $3 \mathrm{~cm}$. in length, from the right wall of the aortic arch just as that vessel begins to descend (Evans, 1936). In his model there is a distinct gap at this level due to the displacement of the œsophagus to the right.

Somewhat more debatable but no less important features are the degree of prominence of the right heart border and the width of the base of the right 
ventricle. In the anterior view the right border, correctly shown to be entirely composed of the right auricle, is too prominent, while the width of the base of the right ventricle is exaggerated. The latter measurement places the interventricular groove and notch rather to the left of the normal, so that the heart apex comes to be formed by both right and left ventricles. This is undoubtedly not true in the normal heart, in which the apex is formed solely of left ventricle. For these reasons we have modified Taipale's model and constructed what we regard as an average normal heart (Fig. 7, Model 1).

The Superior Vena Cava.-Studies of the normal heart post-mortem, after radio-opaque injection, and observations upon the wax-injected heart in situ indicate that the true position of the superior vena cava in relation to the ascending limb of the aortic arch is not properly appreciated. Illustrations of the heart in most anatomical texts and the majority of papier-mâché composition

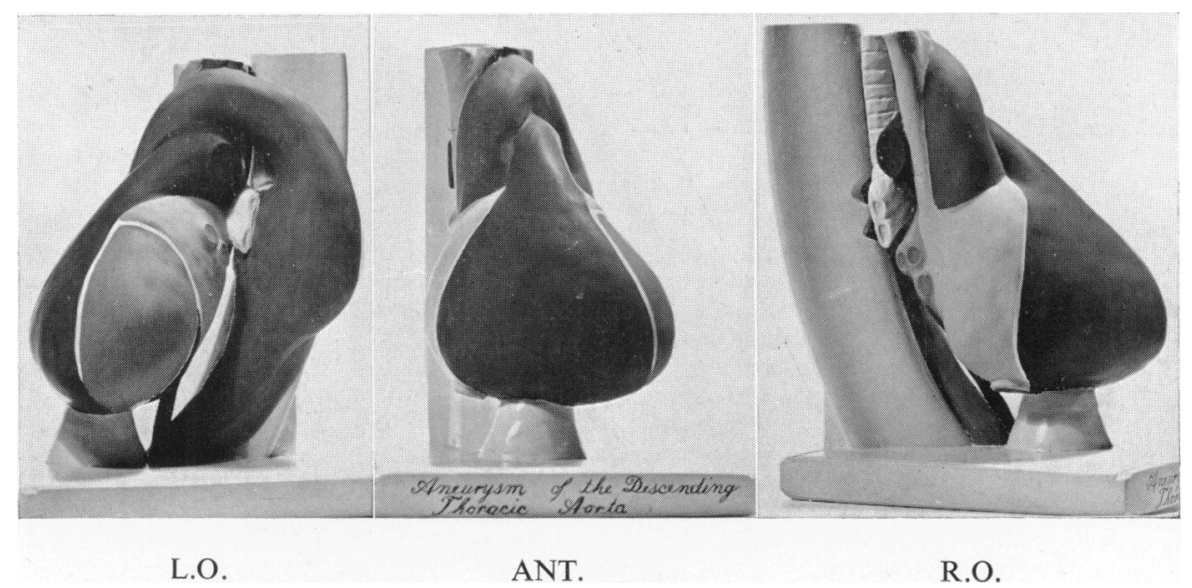

FIG. 14.-Model 8. Aneurysm of the descending thoracic aorta. The heart size and configuration are normal. In the anterior view, the dilated descending aorta is seen well to the left, disappearing behind the heart at the level of the junction of the left auricle and left ventricle. In the left oblique view, the aneurysm, fusiform in type, is seen projecting beyond the left margin of the vertebral column, eroding the latter and adherent anteriorly to the left bronchus, which is stenosed and deformed. In the right oblique view erosion of the anterior aspect of two adjacent vertebræ is seen.

models in anatomical museums portray the superior vena cava as lying well to the right and only slightly posterior to the root of the aorta. This is quite inaccurate. The superior vena cava lies almost wholly posterior to the root of the aorta and rarely projects more than half a centimetre beyond the right aortic border at this level. Thus in a teleradiogram or orthodiagram the right border of the vascular pedicle in its lower third indicates the position of the right border of the ascending aorta. Mainly concerned with the dried, preserved corpse, the anatomist has for decades depicted these two vessels lying in practically the same plane.

The Right Ventricle.-The right border formed by the right ventricle has likewise been inaccurately depicted. If a glass plate is placed over the opened thorax of the corpse and a tracing is made of the heart outline, it will readily be seen that, when it is compared with an orthodiagraphic tracing of the 
same patient taken during life, the right heart border is formed entirely by the right auricle. In the anterior view the right ventricle takes no part in the formation of the lateral heart borders. One exception might be mentioned, namely, the "drop " heart found in tall, spare individuals with a low diaphragm,

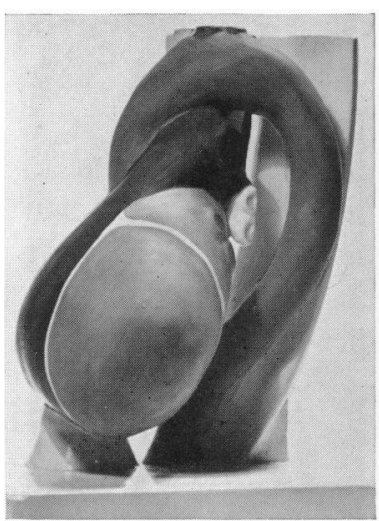

L.O.

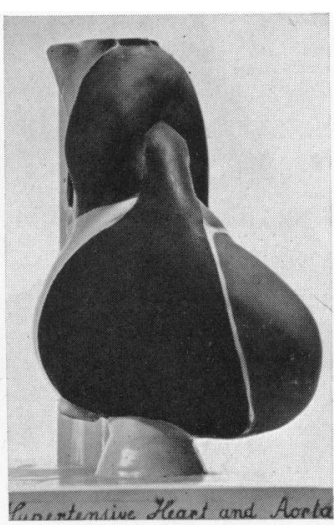

ANT.

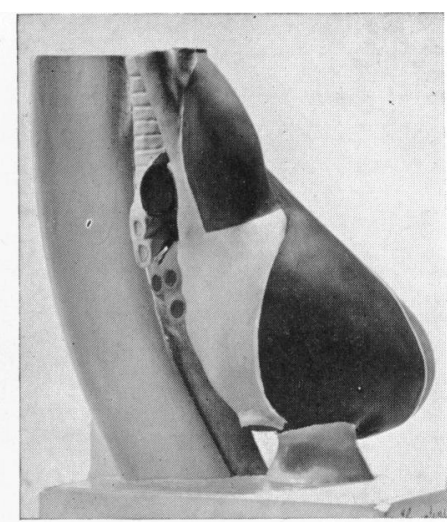

R.O.

FIG. 15.-Model 9. Hypertensive heart and tortuous arteriosclerotic aorta. Characteristic enlargement of the left ventricle and also widening and tortuosity of the whole aorta. In the anterior view, the ascending limb projects to right of the superior vena cava, while the arch runs obliquely backwards to the left, instead of almost directly backwards. The aortic knob is accentuated and the whole arch takes a wide curve, due to lengthening of the aorta. The descending aorta projects posteriorly and to the left and its lower third is kinked as it passes forward to descend through the diaphragm.

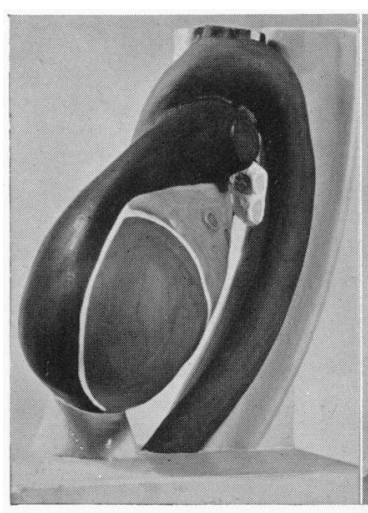

L.O.

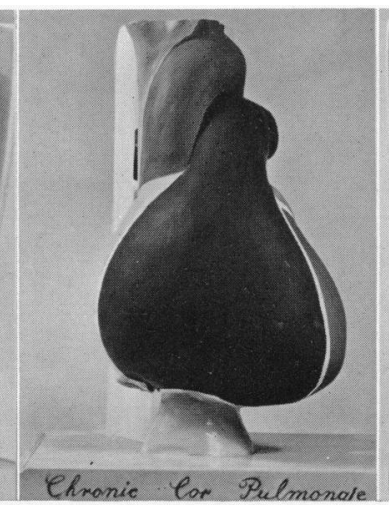

ANT

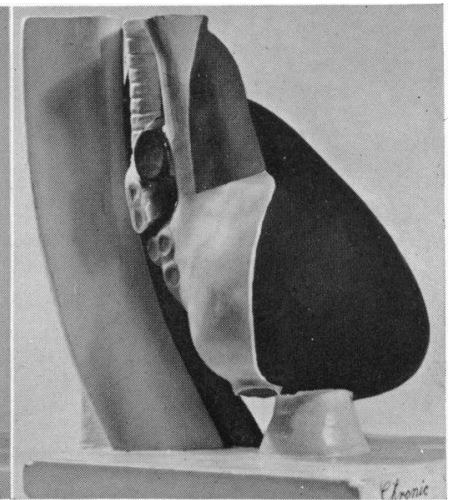

R.O.

FIG. 16.-Model 10. Chronic cor pulmonale. Enlargement of the right ventricle and pulmonary arterial trunk. In the anterior view the pulmonary artery and conus are prominent and form a marked convexity on the left heart border. In the lateral view the anterior border of the heart presents a marked prominence in the region of the conus due to enlargement of the outflow tract of the right ventricle.

in whom the right ventricle may take part in forming a very small segment of the right heart border near the entrance of the inferior vena cava. This point is of some importance as it means that slight enlargement of the right ventricle is not detected in the anterior view ; the outflow tract, which is the first to show signs of enlargement, can only be viewed in the oblique or lateral positions. 
The Left Auricle.-Whether the left auricle takes any part in the formation of the left heart border has been the subject of much debate; modern opinion is that it does not. Indisputable evidence on this point is difficult to obtain, but the impression one has obtained during the course of this study is that,

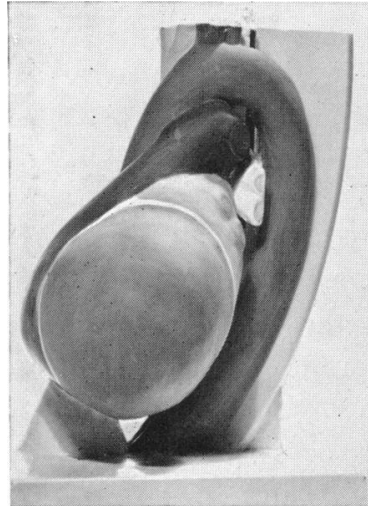

L.O.

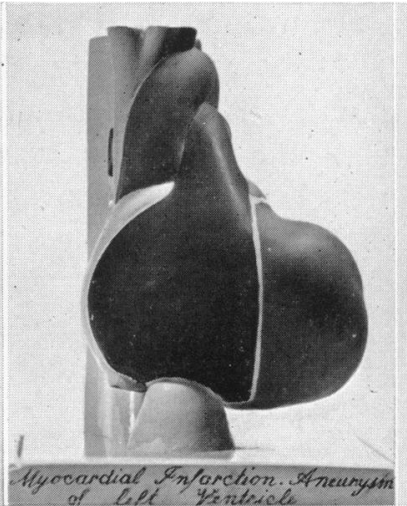

ANT.

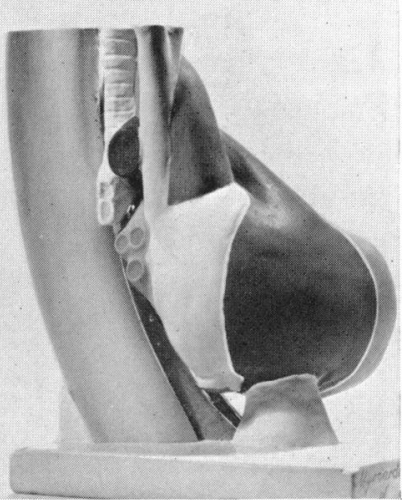

R.O.

Fig. 17.-Model 11. Myocardial infarction and aneurysm of the left ventricle. Boot-shaped appearance of the heart in the anterior view, due to bulging of the left ventricle near the apex. The ventricle projects to the left and posteriorly, is rounded in shape and presents a shallow concavity on its left lateral margin. In the right oblique view there is characteristic " ledging" as the aneurysmal sac bulges forward from the main cardiac mass. In the left oblique view the retrocardiac space is reduced in its lower third.

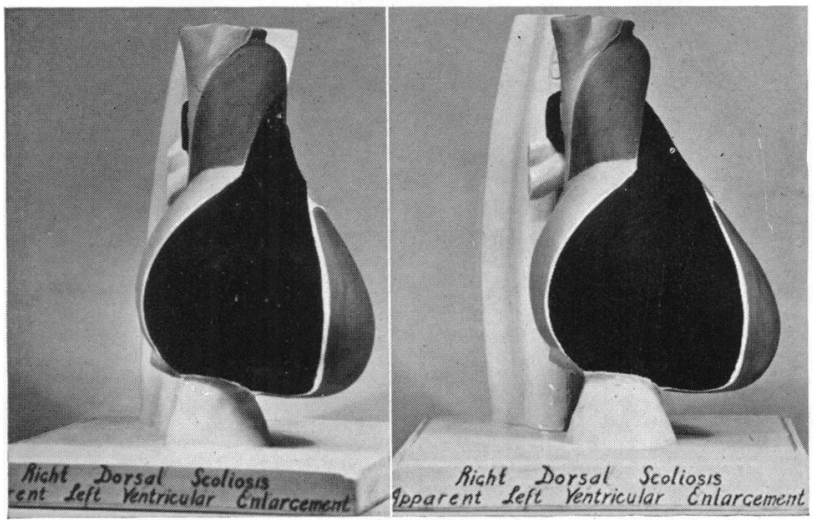

SLight Rotation.

ANT.

Fig. 18.-Model 12. Right dorsal scoliosis with apparent left-sided enlargement of the heart. The moderate, adolescent type of scoliosis gives the impression of left-sided cardiac enlargement with prominence of the aortic knob. When rotated slightly to the right, however, the scoliotic effect is counterbalanced and the heart appears normal. (Parkinson, 1936.)

certainly in some cases, a small segment between the pulmonary artery and left ventricle is formed by the triangular auricular appendage and adjacent wall of the left auricle. In our modification of Taipale's model of a normal heart we have reduced the auricular salient from $3 \mathrm{~cm}$. to $1.5 \mathrm{~cm}$. A longer arc 
is only likely to occur in the "vertical " heart with a long, almost perpendicular, pulmonary artery.

The Pulmonary Arc.--Reference should be made, in passing, to the misconception that prevails in some quarters that the second curve on the left heart border in the teleradiogram or orthodiagram is formed by the conus of the right ventricle. It is sometimes loosely referred to as the "pulmonary conus." The conus of the right ventricle, however, lies well within the limits of the heart shadow in the anterior view. The pulmonary arc is formed by the trunk and left main branch of the pulmonary artery. An opportunity of making direct observations on this question has recently been afforded R. E. Gross (1939) during his operation for ligation of the patent ductus arteriosus. In several cases he states that he has observed the pulmonary arc to be formed mainly by the left pulmonary artery ; clips placed on this vessel at operation delimited the pulmonary arc in a subsequent teleradiogram.

\section{SUMMARY}

A technique has been described whereby life-sized models of the heart in health and disease have been reconstructed. A description of each model in a series of twelve has been furnished, together with photographs of each in the anterior, left oblique, and right oblique views.

With the co-operation of the American Heart Association it has been possible to arrange for their distribution to those interested, in the hope that they will prove useful in the teaching of cardiology and of fluoroscopy of the heart. Enquiries should be addressed to the American Heart Association, Radio City, 50 West 50th Street, New York City, U.S.A.

I wish to tender my acknowledgments and thanks to Dr. Paul D. White for much helpful guidance and criticism during the course of this study, undertaken while holding a Commonwealth Fund Fellowship in the Department of Cardiology, Massachusetts General Hospital, Boston.

\section{REFERENCES}

Evans, W. (1936). The Course of the Esophagus in Health, and in Disease of the Heart and Great Vessels. Medical Research Council, Special Reports Series, No. 208. London.

Gross, R. E. (1939). New Eng. Jour. Med., 220, 510.

Palmieri, G. G. (1921). Arch. Mal. Caur, 14, 440.

Palmieri, G. G. (1929). Acta radiol., 10, 127

Parkinson, J. (1936). Lancet, 1, 1337.

Taipale, L. (1934). Rontgenpraxis, 6, 379. 